\title{
Characteristic Features of the Regulatory Functions of the D-Ribulose 1,5-Bisphosphate Carboxylase/Oxygenase from Spinach
}

\author{
Joachim Vater, Thomas Gaudszun, Benita Lange, Nazmiye Erdin, \\ and Johann Salnikow \\ Institut für Biochemie und Molekulare Biologie, Abteilung Biochemie, Technische Universität \\ Berlin, Franklinstr. 29, D-1000 Berlin 10
}

Z. Naturforsch. 38 c, $418-427$ (1983); received January 27/March 17, 1983

Regulation of Rubisco, Anionic Modulators, Specificity and Mechanism of Action of Dianionic Effectors

Catalysis and regulation of $\mathrm{CO}_{2}$ fixation differ in a characteristic manner in their response to anionic modifiers and the polarity of the reaction medium. Monovalent inorganic anions inhibit catalysis and $\mathrm{CO}_{2}$-activation of the D-ribulose 1,5-bisphosphate carboxylase/oxygenase from spinach, whereas the activity and binding of NADPH and effector sugar phosphates are affected only at appreciably higher concentrations. In contrast such modulators with a dianion structure stimulate $\mathrm{CO}_{2}$ fixation by an increase of the affinity of the enzyme for the activator $\mathrm{CO}_{2}$ and stabilization of the reactive carbamate. Structure-activity studies revealed a broad specificity of the enzyme for these regulatory effects. Essentially amino groups are involved in these processes. Certain organic solvents, as methanol or acetone, stimulate $\mathrm{CO}_{2}$ fixation by a similar modification of the $\mathrm{CO}_{2}$ activation centers, as induced by dianionic effectors. These results infer that such effects are due to a decrease of the polarity at the regulatory centers of the enzyme and a concomitant change of the $\mathrm{pK}$ of the active lysine responsible for the binding of the activator $\mathrm{CO}_{2}$. A correlation of effector binding and activity demonstrates that already low, non-saturating concentrations of such modifiers induce high activation levels of the carboxylase and prevent the dissociation of the activated ternary complex. It is discussed that the central problem concerning the catalytical competence of D-ribulose 1,5-bisphosphate carboxylase/oxygenase (Rubisco) in the presence of active site directed dianionic effectors can be solved kinetically.

\section{Introduction}

Ribulose 1,5-bisphosphate carboxylases/oxygenases [3-phospho-D-glycerate carboxy-lyase (dimerizing) EC 4.1.1.39] are distinguished by marked regulatory properties $[1-4]$. These enzymes can be regulated either homotropically by the substrates $\mathrm{CO}_{2}$ and ribulose 1,5-bisphosphate $\left(\mathrm{RuP}_{2}\right)$ or heterotropically by various chloroplast metabolites [4-14].

Ribulose 1,5-bisphosphate carboxylases/oxygenases are activated by preincubation with $\mathrm{HCO}_{3}^{-}$ and $\mathrm{Mg}^{2+}$. The ternary complex carboxylase $\cdot{ }^{\mathrm{A}} \mathrm{CO}_{2}$. $\mathrm{Mg}^{2+}$ is the active form of those enzymes. The existence of one separate regulatory binding site for

\footnotetext{
Abbreviations: Rubisco, D-ribulose 1,5-bisphosphate carboxylase/oxygenase; $\mathrm{Ru} \mathrm{P} \mathrm{P}_{2}$, ribulose 1,5-bisphosphate; ${ }^{\mathrm{A}} \mathrm{CO}_{2}$, activator $\mathrm{CO}_{2}$; bicine, N,N-bis-(2-hydroxyethyl)-glycine; DTE, dithioerythritol; TNS, 2-p-toluidinonaphthalene-6sulfonate; NMM, N-methylmaleimide; PGO, phenylglyoxal; PLP, pyridoxal 5'-phosphate; EDTA, ethylenediaminetetraacetate.
}

Reprint requests to Priv. Doz. Dr. J. Vater.

0341-0382/83/0500-0418 \$01.30/0
$\mathrm{CO}_{2}$ per catalytically active large subunit $\mathrm{A}$ of the Rubisco has been demonstrated by several authors $[13,15-18]$.

Effector sugar phosphates, as 6-phosphogluconate or fructose 1,6-bisphosphate, stimulate $\mathrm{CO}_{2}$ fixation at relatively low concentrations and inhibit this process at higher concentrations competitively to $\mathrm{RuP}_{2}[4,7,10]$. Previous studies suggested that these agents bind to both the reaction centers of the carboxylase and to separate regulatory binding sites. Recently several authors reported evidence that such type of effectors elicit their stimulating effect through interaction exclusively in the region of the catalytic sites of the Rubisco [11, 12, 14]. It has been demonstrated that the mode of action of these agents is to enhance the affinity of the enzyme for the activator $\mathrm{CO}_{2}$. In this manner the effectors support the activation process and stimulate $\mathrm{CO}_{2}$ fixation. The aim of this publication is a) to investigate the characteristic features of the regulatory functions of the spinach enzyme and b) to clarify, how the Rubisco can remain catalytically competent in the presence of active site directed modifiers. 


\section{Methods and Materials}

\section{Methods}

\section{Enzyme preparations}

Highly purified ribulose 1,5-bisphosphate carboxylase/oxygenase from spinach was prepared essentially as described by Vater and Salnikow [10]. Sepharose 6B was replaced by LKB ultrogel AcA 22. For quantitative binding studies with radioactively labelled effectors the enzyme was additionally purified by gradient centrifugation for $18 \mathrm{~h}$ at $132000 \times g$ in $10-30 \%(\mathrm{v} / \mathrm{v})$ glycerol gradients using a Beckman SW 27-rotor. The specific activity of our preparations was $0.5-1.5 \mu \mathrm{mol} \mathrm{CO}_{2}$ fixed per min and $\mathrm{mg}$ protein.

\section{Assays for $\mathrm{CO}_{2}$ fixation}

1) Studies with effectors. The effector activity is defined as the excess carboxylation of $\mathrm{RuP}_{2}$ in the presence of an effector in per cent over the carboxylation without effector which was taken as the reference and set to $100 \%$.

Assay method a: Samples of the spinach carboxylase were preincubated for $10 \mathrm{~min}$ in an activation mixture containing $0.1 \mathrm{M}$ bicine-KOH-buffer, $\mathrm{pH}=8.0$; variable effector concentrations; $0.1 \mathrm{~mm}$ $\mathrm{NaH}^{14} \mathrm{CO}_{3} ; 10 \mathrm{~mm} \mathrm{MgCl} 2 ; 0.1 \mathrm{~mm}$ sodium ethylenediaminetetraacetate (EDTA) and $1 \mathrm{~mm}$ DTE. The carboxylase reaction was started with $0.5 \mathrm{mM} \mathrm{RuP}_{2}$ and assayed for $15-60 \mathrm{~s}$ at limiting bicarbonate concentration $(0.1 \mathrm{~mm})$. The assays were terminated with $0.2 \mathrm{~N} \mathrm{HCl}$. Aliquots were dried and the acid stable product was determined by scintillation counting. $\mathrm{CO}_{2}$ depleted buffers which were prepared similar to the procedure reported by Hatch and Jensen [11] were used for all experiments with effectors.

Assay method b: Samples of the enzyme were preincubated for $10 \mathrm{~min}$ in the same medium as under a and then diluted 100-200 fold into a reaction mixture containing $0.1 \mathrm{M}$ bicine- $\mathrm{KOH}$-buffer, $\mathrm{pH}=8.0 ; 10 \mathrm{~mm} \mathrm{NaH}{ }^{14} \mathrm{CO}_{3} ; 10 \mathrm{~mm} \mathrm{MgCl}_{2} ; 0.5 \mathrm{~mm}$ $\mathrm{RuP}_{2} ; 0.5 \mathrm{~mm}$ EDTA and $1 \mathrm{~mm}$ DTE. In contrast to method a the carboxylase activity was assayed at saturating bicarbonate concentration $(10 \mathrm{~mm})$.

2) Determination of the $\mathrm{CO}_{2}$ activation constant $K_{\text {act }}\left(\mathrm{CO}_{2}\right) . K_{\text {act }}\left(\mathrm{CO}_{2}\right)$ which is defined as the $\mathrm{CO}_{2}$ concentration producing half maximal activation of the Rubisco was estimated according to the procedure published by Hatch and Jensen [11].

The enzyme was activated $10 \mathrm{~min}$ in activation mixtures containing variable $\mathrm{NaHCO}_{3}$ concentrations and the effector concentrations indicated in Table I. The carboxylation reaction was initiated by adding $50 \mu \mathrm{l}$ of an activation mixture to $450 \mu \mathrm{l}$ reaction mixture specified under assay method $b$. Reaction time: $30 \mathrm{~s}$.

\section{Binding studies with effectors}

1) Quantitative binding of $\left[{ }^{14} \mathrm{C}-6\right]$ phosphogluconate and $\left[{ }^{14} \mathrm{C}\right]$ fructose 1,6 -bisphosphate to the spinach carboxylase was detected by the ultrafiltration technique. An Amicon micropartition system MPS-1 was used. After preincubation of the enzyme with effectors in the presence of $10 \mathrm{mM} \mathrm{MgCl}_{2}$ the enzyme-ligand-complex was separated from the free ligand by centrifugation through YMB-filters at $1500 \times g$.

2) Fluorimetric binding studies were performed as published previously $[10,19]$. 2-p-toluidinonaphthalene-6-sulfonate (TNS) was used as hydrophobic reporter group. Corrected difference emission spectra of the enzyme - TNS - and the enzyme TNS - ligand complexes were recorded with a Perkin Elmer MPF 44 spectrofluorimeter in combination with a differential corrected spectra attachment DCSU-2.

Most experiments were performed at $25^{\circ} \mathrm{C}$, as otherwise indicated in the legends.

\section{Synthesis of 6-phospho $\left[{ }^{14} \mathrm{C}\right]$ gluconate}

The effector was synthesized essentially as described Badger and Lorimer [12]. 6-Phosphogluconate was prepared enzymatically from $\mathrm{D}-\mathrm{U}-\left[{ }^{14} \mathrm{C}\right]$ glucose using hexokinase and glucose 6-phosphate dehydrogenase, with a phosphoenolpyruvate-pyruvate kinase ATP regenerating system. The product was purified by ion exchange chromatography on sephadex QAE-25. Approx. 90\% of the whole ${ }^{14} \mathrm{C}$ label applied to the column appeared as a single peak which was free of nucleotides as checked by the absorption at $260 \mathrm{~nm}$ and the orcinol reaction. Further processing of the product obtained and determination of its specific activity were performed as indicated by Badger and Lorimer [12]. The ${ }^{14} \mathrm{C}$ content of the preparation was checked by scintillation counting. The 6-phosphogluconate concentra- 
tion was determined from the absorbance change of $\mathrm{NADPH}$ at $340 \mathrm{~nm}$ in the 6-phosphogluconate dehydrogenase assay.

The $\left[{ }^{14} \mathrm{C}\right]$-specific activity of the product corresponded within $5 \%$ with that of the starting material $\left[{ }^{14} \mathrm{C}\right] \mathrm{glucose}(3.1 \mathrm{mCi} / \mathrm{mmol})$.

\section{Materials}

$\mathrm{RuP}_{2}, \mathrm{NADPH}, \mathrm{PLP}$ and the effector sugar phosphates were obtained from Sigma (München/BRD), PGO from Serva (Heidelberg/BRD) and NMM from United States Biochemical Corp. (Cleveland/ USA). Anionic modifiers were commercial grade products of Sigma and Merck (Darmstadt/BRD). $\mathrm{NaH}^{14} \mathrm{CO}_{3}, \quad\left[{ }^{14} \mathrm{C}\right]$ fructose $\quad$ 1,6-bisphosphate and $\left[{ }^{14} \mathrm{C}\right]$ glucose were purchased from Amersham, Buchler (Braunschweig/BRD).

\section{Results}

I) The effects of monovalent anions on the catalytic and regulatory properties of D-ribulose 1,5-bisphosphate carboxylases/oxygenases

In Fig. 1 it is demonstrated that $\mathrm{CO}_{2}$ fixation is inhibited by $\mathrm{NaCl}$. The carboxylation of $\mathrm{RuP}_{2}$ has been measured under limiting $\mathrm{CO}_{2}$ concentrations $\left(0.1 \mathrm{mM} \mathrm{NaHCO}_{3} ; 10 \mathrm{mM} \mathrm{Mg}^{2+}\right)$ as a function of the

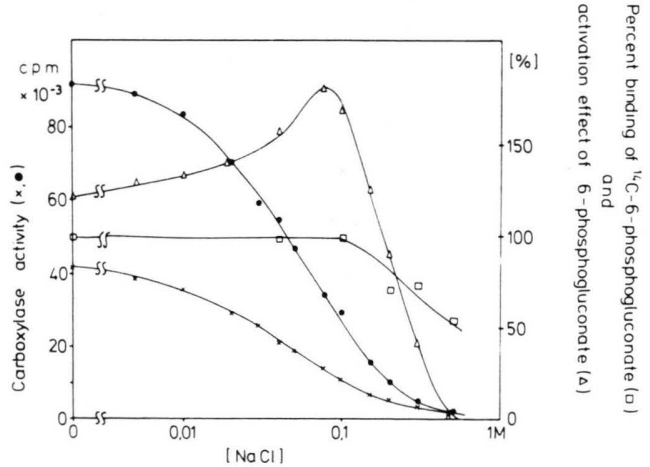

Fig. 1. Carboxylase activity in the presence of $20 \mu \mathrm{M}$ 6-phosphogluconate $(\bullet)$ and without effector $(\times)$ as well as effector activity $(\Delta)$ and binding ( $\square$ ) of 6-phosphogluconate as a function of the $\mathrm{NaCl}$ concentration. For the measurement of $\mathrm{CO}_{2}$ fixation assay method a was used. Reaction mixtures contained $0.1 \mathrm{~mm} \mathrm{NaHCO}, 10 \mathrm{~mm}$ $\mathrm{MgCl}_{2}$ and variable $\mathrm{NaCl}$ concentrations. The carboxylation rate in the absence of $\mathrm{NaCl}$ and effector was $0.21 \mu \mathrm{mol} \mathrm{mg}$ protein ${ }^{-1} \mathrm{~min}^{-1}(0.17 \mathrm{mg}$ protein per assay). Effector binding was detected by the ultrafiltration technique.
$\mathrm{NaCl}$ concentration in the presence of $20 \mu \mathrm{M}$ 6-phosphogluconate and without the effector. Under these conditions the carboxylase reaction is inhibited by the salt in the range of $10-500 \mathrm{~mm} \mathrm{NaCl}$. In contrast both the binding of $\left[{ }^{14} \mathrm{C}-6\right]$ phosphogluconate and its effector activity are more stable against $\mathrm{NaCl}$ inhibition than the catalytic process. They start to decline at about $0.1 \mathrm{M} \mathrm{NaCl}$, when $\mathrm{CO}_{2}$ fixation is already reduced to a level of approx. $25-30 \%$. Similar results have been obtained for the effectors NADPH and fructose 1,6-bisphosphate. There is no salt effect on effector binding and activity at lower levels especially those that are comparable with the effector concentrations.

The inhibition of $\mathrm{CO}_{2}$ fixation by various monovalent anions follows the Hofmeister series for the lyotropic properties of such agents:

$$
\mathrm{ClO}_{4}^{-}>\mathrm{SCN}^{-}>\mathrm{CF}_{3} \mathrm{COO}^{-}>\mathrm{NO}_{3}^{-}>\mathrm{Br}^{-}>\mathrm{Cl}^{-} \text {. }
$$

Similar results have been obtained at salt concentrations of 20 and $200 \mathrm{~mm}$. On the other hand the activity of effectors, as 6-phosphogluconate, again is not decreased under these conditions. From Table I it is apparent that various monovalent anions function as negative effectors of the carboxylase process. They increase the $\mathrm{CO}_{2}$-activation constant $K_{\text {act }}$ $\left(\mathrm{CO}_{2}\right)$ and, therefore, inhibit the formation of the active ternary complex enzyme $\cdot{ }^{\mathrm{A}} \mathrm{CO}_{2} \cdot \mathrm{Mg}^{2+} \cdot K_{\text {act }}$ $\left(\mathrm{CO}_{2}\right)$ which is defined as the $\mathrm{CO}_{2}$ concentration for half maximal $\mathrm{CO}_{2}$ activation of the carboxylase was estimated from double reciprocal diagrams of the $\mathrm{CO}_{2}$ activation of the enzyme as a function of the $\mathrm{CO}_{2}$ concentration according to the method of Hatch and Jensen [11].

Similar results as for the monovalent anions listed in Table I have been obtained also for anions of monocarboxylic acids, like acetate, propionate, butyrate, acetoacetate or ketovalerate and for sugar monophosphates, as ribose 5-phosphate or fructose 6-phosphate.

\section{II) Studies with dianionic effectors of D-ribulose 1,5-bisphosphate carboxylases/oxygenases}

1) Properties of dianionic effectors and specificity of the effector binding sites

In contrast to monovalent anions bivalent inorganic anions, like $\mathrm{SO}_{4}^{2-}$ or $\mathrm{HPO}_{4}^{2-}$ and, in particular, reagents with a dianion structure, like $\mathrm{C} 2-\mathrm{C} 6$ dicarboxylic acids and sugar bisphosphates with an 
Table I. The maximal activity of various effectors as determined by the dilution method and $\mathrm{CO}_{2}$-activation constants in the presence of modulators of the D-ribulose 1,5-bisphosphate carboxylase/oxygenase from spinach. For the determination of the maximal effector activity samples of the enzyme were preincubated in an activation mixture at high effector concentrations (column 2) and then diluted 200 fold into a reaction mixture, as indicated under Methods. The carboxylation rate in the absence of effector was $0.39 \mu \mathrm{mol} \cdot \mathrm{mg}$ protein ${ }^{-1} \cdot \mathrm{min}^{-1}(0.022 \mathrm{mg}$ protein in the reaction mixture). The effector concentrations (column 4) for the determination of the $\mathrm{CO}_{2}$-activation constants refer to the maxima of effector profiles, as shown in Fig. 2.

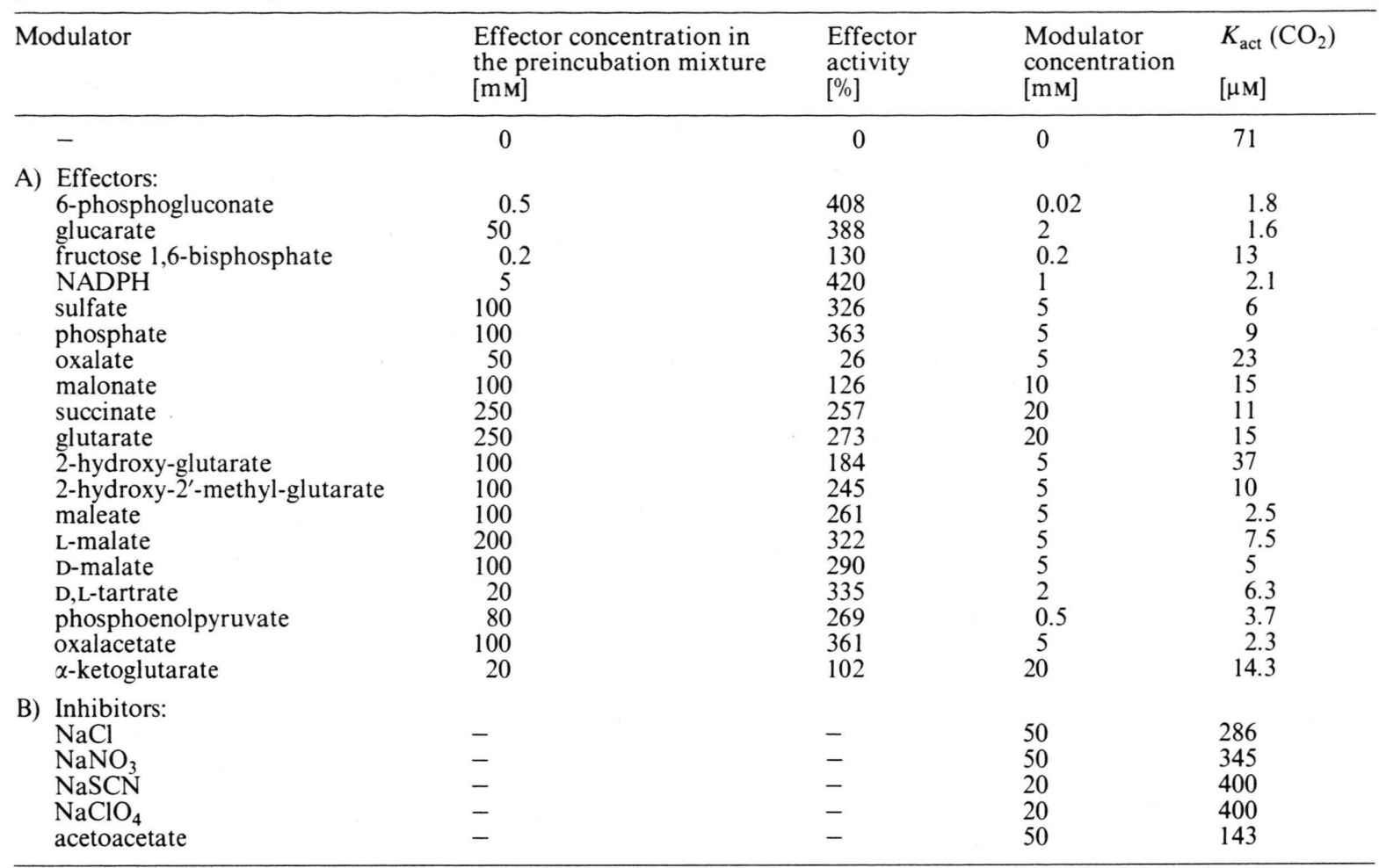

appropriate chain length of not more than $7 \mathrm{C}$ atoms function as potent effectors of $\mathrm{CO}_{2}$ fixation. A collection of more than 20 of such substances is presented in Table I in order to deduce structureactivity relationships and to clarify the specificity of the effector binding site.

All these effectors are distinguished by the following characteristic properties:

a) They enhance the carboxylation reaction at relatively low concentration, when the enzyme is in a limited activation state and inhibit this process at higher concentrations, as is demonstrated in Fig. 2 for some of these agents. The inhibition occurs competitively to the substrate $\mathrm{RuP}_{2}$. All the diagrams in Fig. 2 are characterized by an effector maximum that results from a superposition of the stimulation and inhibition effects induced by these compounds. These experiments were performed at $0.1 \mathrm{~mm} \mathrm{NaHCO}_{3}$ and $20 \mathrm{~mm} \mathrm{MgCl}_{2}$.

b) All the effectors in Table I which equilibrate rapidly with the enzyme decrease $K_{\text {act }}\left(\mathrm{CO}_{2}\right)$, i.e. they stabilize the active ternary complex enzyme - ${ }^{\mathrm{A}} \mathrm{CO}_{2} \cdot \mathrm{Mg}^{2+}$ and support $\mathrm{CO}_{2}$ fixation. The effector concentrations for the determination of $K_{\text {act }}$ $\left(\mathrm{CO}_{2}\right)$ refer to the maxima of effector activity profiles, as shown in Fig. 2. The stabilization of the reactive carbamate is also obvious from Fig. 3 which demonstrates that the dissociation of this intermediate is retarded under such conditions. In order to compare the full regulatory capacity of such effectors, the dilution method [12, 14] was applied. The concept of this technique is to saturate the effector binding sites and thus to develop the maximal activation effect. Under these conditions, 


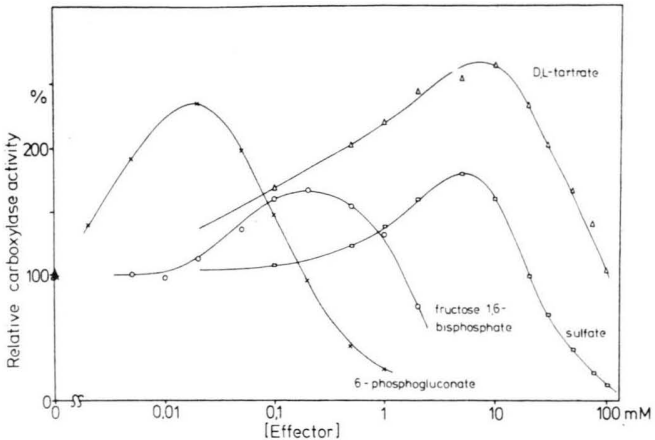

Fig. 2. Relative carboxylase activity as a function of the effector concentration (assay method a). The reference without effector $(100 \%)$ corresponds to a carboxylation rate of $0.18 \mu \mathrm{mol} \mathrm{mg} \mathrm{protein}{ }^{-1} \min ^{-1}(0.18 \mathrm{mg}$ protein per assay).

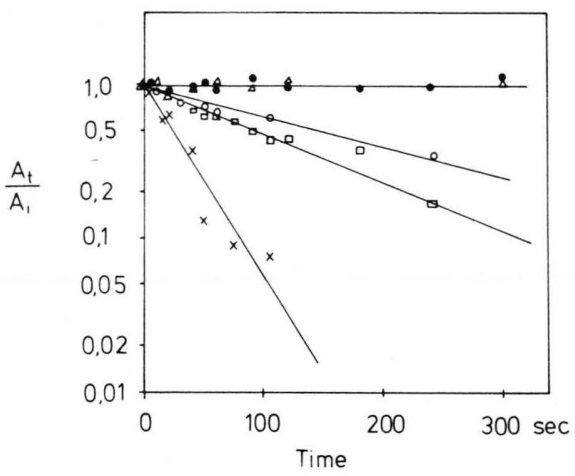

Fig. 3. Effector dependent modification of the dissociation of the activated ternary complex carboxylase ${ }^{A} \mathrm{CO}_{2} \cdot \mathrm{Mg}^{2+}$ at $10^{\circ} \mathrm{C}$. The enzyme was first activated for $1 \mathrm{~h}$ in $0.1 \mathrm{M}$ bicine-KOH-buffer, $\mathrm{pH}=8.0$ containing $10 \mathrm{~mm} \mathrm{NaHCO}$, $10 \mathrm{~mm} \mathrm{MgCl}, 0.1 \mathrm{~mm}$ EDTA and $1 \mathrm{~mm}$ DTE. $10 \mu \mathrm{l}$ aliquots of the reaction mixtures were diluted 100 fold into $990 \mu \mathrm{l} \mathrm{CO}$-depleted $0.1 \mathrm{M}$ bicine-buffer, $\mathrm{pH}=8.0,0.1 \mathrm{~mm}$ EDTA and $1 \mathrm{~mm}$ DTE. The dilution medium was either free of effector $(\mathrm{x})$ or contained $1 \mu \mathrm{M}(0) ; 20 \mu \mathrm{M}(\bullet)$ and $200 \mu \mathrm{M}(\triangle)$ 6-phosphogluconate or $20 \%(\mathrm{v} / \mathrm{v})$ acetone $(\square)$. At the indicated times after dilution of the enzyme $\mathrm{CO}_{2}$ fixation was started by addition of the reaction components $\left(10 \mathrm{~mm} \mathrm{NaHCO}, 10 \mathrm{~mm} \mathrm{MgCl}_{2}\right.$ and $0.5 \mathrm{~mm} \mathrm{RuP}$ ) and assayed for $30 \mathrm{~s}$. The ratio of the activity $A_{\mathrm{t}}$ at time $t$ and the initial activity $A_{\mathrm{i}}$ at $t=0$ was plotted halflogarithmically as a function of the length of the time intervals between dilution and assay of the enzyme.

however, the enzyme is completely inhibited and therefore catalytically incompetent, because Badger and Lorimer [12] have shown that such effectors bind exclusively at the reaction centers of the carboxylase within the $\mathrm{RuP}_{2}$ binding domain. For the detection of the activation state of the enzyme the reaction mixtures have to be diluted sufficiently.
The experiments demonstrated in Fig. 4 and Table I were performed, as follows: Samples of the spinach enzyme were saturated with effectors by preincubation at high inhibitory modifier concentrations and low $\mathrm{CO}_{2}$ activation conditions $\left(0.1 \mathrm{~mm} \mathrm{NaHCO}_{3}\right.$; $10 \mathrm{mM} \mathrm{MgCl}_{2}$ ). Afterwards they were diluted 200 fold into the assay mixture. By this procedure the effector concentrations in the assay were reduced to levels at which most of these compounds do not affect $\mathrm{CO}_{2}$ fixation appreciably. The assay time was reduced as far as possible (15s) to establish that the activation state of the enzyme reached during preincubation was not changed significantly during the assay. As demonstrated for 6-phosphogluconate in Fig. 4 the effector activity increases under such conditions up to high effector concentrations which normally inhibit the carboxylase reaction completely (see Fig. 2). The maximal activation levels obtained by the dilution method are summarized in Table I. If $\mathrm{RuP}_{2}$ and effectors compete for a common binding site at the enzyme, one should expect that also $\mathrm{RuP}_{2}$ displays a stabilizing effect on the reactive carbamate complex which is the activated form of the Rubisco. To test this assumption we added $\mathrm{RuP}_{2}$ in variable concentration to the activation mixture. Under such experimental conditions $\mathrm{CO}_{2}$ fixation proceeded already in the preincubation medium, but the substrate pool was not completely consumed during the activation period. Our results show that also $\mathrm{RuP}_{2}$ induces a decrease of $K_{\text {act }}$ $\left(\mathrm{CO}_{2}\right)$ similar to the effector anions. At initial concentrations of 0.04 and $0.2 \mathrm{mM} \mathrm{RuP}_{2}$ in the activa-

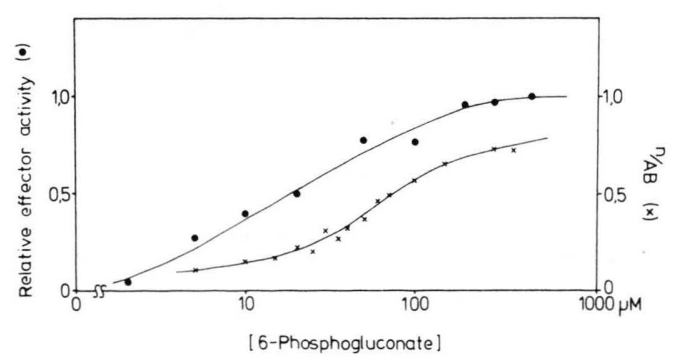

Fig. 4. Relative effector activity of 6-phosphogluconate $(\bullet)$ and $\left[{ }^{14} \mathrm{C}-6\right]$ phosphogluconate binding $(x)$ to the spinach carboxylase as a function of the effector concentration. $\mathrm{AB}$ is one protomer of the carboxylase which consists of one large and one small subunit $\mathrm{A}$ and $\mathrm{B} . n / \mathrm{AB}$ indicates the number of effectors bound per protomer $A B$. Assay method $b$; the activation mixtures were diluted 200 fold with the assay mixture. The maximum effector activity of 6 -phosphogluconate was $408 \%$. $\left[{ }^{14} \mathrm{C}-6\right]$ phosphogluconate binding was detected by the ultrafiltration method. 
tion mixture $K_{\text {act }}\left(\mathrm{CO}_{2}\right)$ of 64 and $20 \mu \mathrm{M}$, respectively, were obtained compared to $K_{\text {act }}\left(\mathrm{CO}_{2}\right)=$ $71 \mu \mathrm{M}$ in the absence of a modifier.

2) Correlation between effector activity and effector binding

In order to clarify the question, how ribulose 1,5-bisphosphate carboxylases/oxygenases remain catalytically competent in the presence of effectors that interact at the reaction centers we correlated activity measurements with binding studies.

In Fig. 3 measurements of the dissociation kinetics of the reactive carbamate of the carboxylase have been performed. The enzyme was activated in the presence of each $10 \mathrm{~mm} \mathrm{NaHCO}_{3}$ and $\mathrm{MgCl}_{2}$ for $30 \mathrm{~min}$ at $25^{\circ} \mathrm{C}$. The activation mixture was then diluted 100 fold into $\mathrm{CO}_{2}$-depleted buffer at $10^{\circ} \mathrm{C}$. Under these conditions the previously formed active ternary complex decomposes in a first order kinetics with a half life time of $t_{1 / 2}=28 \mathrm{~s}$. This process is retarded already at very low 6-phosphogluconate concentrations as $1 \mu \mathrm{M}\left(t_{1 / 2}=145 \mathrm{~s}\right)$. In the presence of $20 \mu \mathrm{M}$ 6-phosphogluconate which corresponds to its effector maximum at low $\mathrm{CO}_{2-}$ concentrations, when assayed by method a (see Fig. 2), the reactive carboxylase-carbamate complex is completely stabilized. Under such conditions only small portions of the reaction centers are occupied by the modifier $(6 \%$ at $1 \mu \mathrm{M}$ and $16 \%$ at $20 \mu \mathrm{M}$ resp.). Obviously relatively low, non-saturating effector concentrations induce high activation levels of the carboxylase. This conclusion is supported by the experiments shown in Fig. 4 which indicate that the pofile for the activation of the enzyme is shifted to lower modulator concentrations compared to effector binding. At $20 \mu \mathrm{M}$ 6-phosphogluconate a nearly threefold increase of the carboxylation rate is observed which is more than half of the total stimulation effect induced by this effector. Similar results have been obtained for other effectors.

These data are also consistent with the information derived from competition experiments with combinations of two effectors. In Fig. 5 the action of fructose-1,6-bisphosphate on the binding and activity of 6-phosphogluconate is shown. In a series of experiments fructose 1,6-bisphosphate in increasing concentration was added to the preincubation mixture along with $20 \mu \mathrm{M}$ 6-phosphogluconate. Also in this case the stimulation effect of 6-phosphogluconate is more strongly affected by the

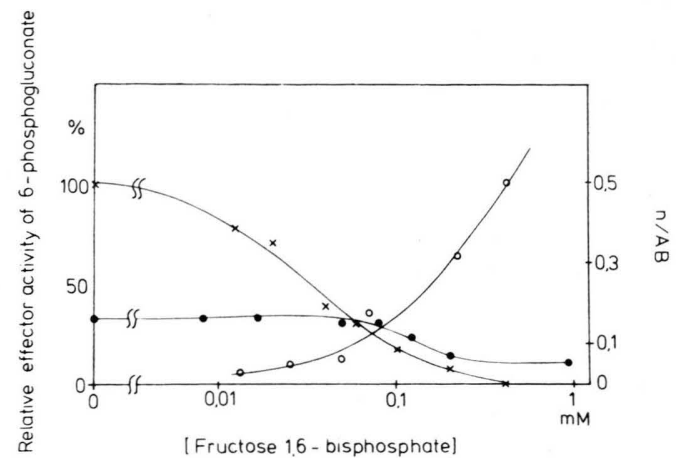

Fig. 5. Relative effector activity of 6-phosphogluconate $(x)$ and $\left[{ }^{14} \mathrm{C}-6\right]$ phosphogluconate binding $(\bullet)$ as a function of the fructose 1,6-bisphosphate concentration as well as the binding profile of fructose 1,6-bisphosphate (O). All samples contained $20 \mu \mathrm{M}$ 6-phosphogluconate. The effector activity of this agent was measured by assay method a. The stimulation effect in the absence of fructose 1,6-bisphosphate was $278 \%$. The carboxylation rate under these conditions was $0.1 \mu \mathrm{mol} \cdot \mathrm{mg}$ protein ${ }^{-1} \cdot \min ^{-1} \quad(0.22 \mathrm{mg}$ protein per assay). Both effectors were added simultaneously to the preincubation mixtures. Effector binding was detected by the ultrafiltration technique.

second modifier than its binding. For example when only $10 \%$ of the effector binding sites are occupied by fructose 1,6-bisphosphate, a loss of $70 \%$ of the effector activity of 6-phosphogluconate is observed. Obviously fructose 1,6-bisphosphate interacts more rapidly with most of the free effector binding sites than 6-phosphogluconate and displays its specific activation of the enzyme. This conclusion is consistent with preliminary results of the kinetic analysis of effector binding using rapid detection techniques (J. Vater and N. Erdin unpublished). Only at higher concentrations competition between both effectors occurs which leads to a displacement of bound 6-phosphogluconate.

\section{The effect of the polarity of the reaction medium on catalysis and regulation of $\mathrm{CO}_{2}$ fixation}

In Figs. $6 \mathrm{a}$ and $\mathrm{b}$ it is demonstrated that the effects of some organic solvents on the $\mathrm{CO}_{2}$ fixation process are similar to the action of dianionic effectors (see Fig. 2). Solvents, as methanol, ethanol or acetone with dielectric constants between 20-40, stimulate the carboxylation reaction at relatively low concentrations $(1-15 \%, \mathrm{v} / \mathrm{v})$, if assayed at limiting bicarbonate concentrations (Fig. 6a). These compounds stabilize the active ternary complex enzyme $\cdot{ }^{A} \mathrm{CO}_{2} \cdot \mathrm{Mg}^{2+}$, as is apparent from the 

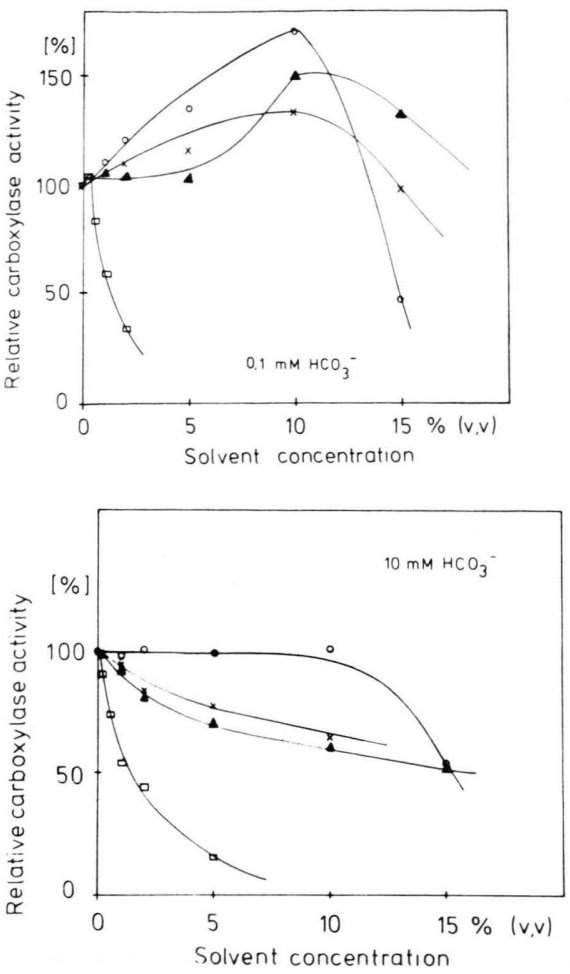

Fig. 6. Relative carboxylase activity as a function of the concentration of various organic solvents in the reaction mixtures. For the measurement of $\mathrm{CO}_{2}$ fixation assay method a was used in the presence of either a) limiting $(0.1 \mathrm{~mm})$ or b) saturating $(10 \mathrm{~mm})$ bicarbonate concentrations. ( $\times$ ) methanol; (O) ethanol; $(\mathbf{\Delta})$ acetone; ( $\square$ ) dioxane. The carboxylation rates in the absence of solvents were 0.21 and $1.34 \mu \mathrm{mol} \mathrm{mg} \mathrm{protein}{ }^{-1} \mathrm{~min}^{-1}$ at $0.1 \mathrm{~mm}$ and $10 \mathrm{mM} \mathrm{NaHCO}_{3}$, respectively $(0.28 \mathrm{mg}$ protein per assay).

kinetic experiment in Fig. 3. At $10^{\circ} \mathrm{C}$ the half life time $t_{1 / 2}=28 \mathrm{~s}$ for the dissociation of the reactive carbamate is increased more than three-fold $\left(t_{1 / 2}=\right.$ $90 \mathrm{~s}$ ), if $20 \%$ acetone are added to the preincubation medium. This is also obvious from a decrease of the $K_{\text {act }}\left(\mathrm{CO}_{2}\right)$ in the presence of such solvents. When
$8 \%(\mathrm{v} / \mathrm{v})$ of methanol, ethanol or acetone were added to the reaction mixture, $K_{\text {act }}\left(\mathrm{CO}_{2}\right)$ data of $54 ; 41$ and $38 \mu \mathrm{M}$, respectively, have been measured compared to $K_{\text {act }}\left(\mathrm{CO}_{2}\right)=71 \mu \mathrm{M}$ without addition of solvent.

The stimulating effects of such solvents are abolished by the addition of dianionic effectors, as $20 \mu \mathrm{M}$ 6-phosphogluconate, for example. At solvent concentrations higher than $10-15 \%(\mathrm{v} / \mathrm{v}) \mathrm{CO}_{2}$ fixation is inhibited and the enzyme tends to precipitate. Also at saturating bicarbonate and $\mathrm{Mg}^{2+}$ concentrations which transform the carboxylase to the activated state, the solvent induced enhancement of the carboxylation rate disappears and only the inhibition phase is observed (Fig. 6b).

If solvents with low dielectric constants, as, for example, dioxane or tetrahydrofurane were applied, only weak stimulation effects have been found at concentrations between $0.03-1 \%(\mathrm{v} / \mathrm{v})$, if assayed at limiting bicarbonate concentrations. In this case the inhibition predominates, as is shown in Figs. $6 \mathrm{a}$ and $b$ for dioxane.

\section{IV) An analysis of functional groups involved in the binding of anionic effectors}

Several authors [20-24] have demonstrated that specific cysteinyl, lysyl, arginyl and histidyl residues are essential for the catalysis and regulation of $\mathrm{CO}_{2}$ fixation. In order to characterize the binding sites for dianionic effectors of the spinach carboxylase we examined the functional groups involved in the binding and activity of such compounds.

In Table II the effects of a) N-methyl-maleimide (NMM) as a thiol inhibitor, b) pyridoxal 5'-phosphate (PLP), a reagent for amino groups of reactive lysine residues and c) phenylglyoxal (PGO) as an arginine specific modifier were investigated.

Table II. The effect of some group specific reagents on $\mathrm{CO}_{2}$-fixation as well as on the effector activity and binding of 6-phosphogluconate. Assays and detection of effector binding were performed as indicated under Methods. The 6-phosphogluconate concentration in the reaction mixtures with effector (experiments b and c) was $20 \mu \mathrm{M}$. The carboxylation rate in the absence of inhibitor $(100 \%)$ was $0.15 \mu \mathrm{mol} \mathrm{mg}$ protein ${ }^{-1} \mathrm{~min}^{-1}(0.18 \mathrm{mg}$ protein per assay).

\begin{tabular}{llll}
\hline Reagent & a) $\mathrm{CO}_{2}$-fixation & $\begin{array}{l}\text { b) Effector activity of } \\
\text { 6-phosphogluconate } \\
{[\%]}\end{array}$ & $\begin{array}{l}\text { c) Binding of } \\
\text { 6-phosphogluconate } \\
{[\%]}\end{array}$ \\
\hline- & {$[\%]$} & 100 & 100 \\
$10 \mathrm{~mm}$ Phenylglyoxal & 100 & 620 & 100 \\
$0.5 \mathrm{~mm}$ N-methylmaleimide & 8.5 & 154 & 100 \\
$0.5 \mathrm{~mm}$ Pyridoxal 5'-phosphate & 20 & 18 & 55
\end{tabular}


The results obtained show that under reaction conditions, when $\mathrm{CO}_{2}$ fixation is reduced to $10-20 \%$ of its original rate, the effector binding of 6-phosphogluconate is not impaired by NMM and PGO. The activity of this effector is even enhanced in the presence of these inhibitors. The reason for this increase remains to be clarified. In contrast lysine specific reagents, as PLP or 2,4,6-trinitrobenzenesulfonate efficiently reduce $\mathrm{CO}_{2}$ fixation as well as binding and activity of 6-phosphogluconate. Similar results have been achieved for some other effectors from the collection in Table I.

\section{Discussion}

The in vivo levels of $\mathrm{CO}_{2}$ and $\mathrm{Mg}^{2+}$ in the stroma of chloroplasts $\left(10 \mu \mathrm{M} \mathrm{CO}, 5-10 \mathrm{~mm} \mathrm{Mg} \mathrm{Mg}^{2+}\right.$ at $\mathrm{pH}=8$ ) cannot account for the high $\mathrm{CO}_{2}$ fixation rates observed under physiological conditions. The Rubisco would be retained mainly in its inactive form. Efforts have been made to clarify this discrepancy.

Several authors $[4,5,7-12,14]$ have demonstrated that the carboxylation and oxygenation of $\mathrm{RuP}_{2}$ can be modulated in vitro by certain anionic chloroplast metabolites. A few of them, as for example, NADPH or 6-phosphogluconate, stimulate these processes at suboptimal $\mathrm{CO}_{2}$ and $\mathrm{Mg}^{2+}$ concentrations and may, therefore, play an important role in the in vivo regulation of photosynthetic $\mathrm{CO}_{2}$ fixation.

In this publication we want to emphasize that the effects of such modifiers on the catalysis and regulation of the carboxylation process can be classified depending on their anionic structure. Our results demonstrate a fundamental difference in the mode of action of monovalent anions and modulators with a dianion structure.

Monovalent anions predominantly inhibit $\mathrm{CO}_{2}$ fixation and the formation of the active ternary complex carboxylase ${ }^{\mathrm{A}} \mathrm{CO}_{2} \cdot \mathrm{Mg}^{2+}$, while the activity and binding of NADPH and effector sugar phosphates is impaired only at appreciably higher concentrations.

Though the effects of such anions studied in this publication occur under nonphysiological conditions they reflect characteristic differences in the reactivity of functional elements involved in the catalysis and regulation of $\mathrm{CO}_{2}$ fixation.

In contrast bivalent anions, like phosphate and sulfate as well as some chloroplast metabolites with a dianionic structure (6-phosphogluconate, fructose, 1,6-bisphosphate etc.) and structurally related compounds increase the affinity of the carboxylase for the activator $\mathrm{CO}_{2}$ and stabilize the active ternary complex. Recent investigations $[12,14]$ characterize such modifiers as $\mathrm{RuP}_{2}$ like, active site directed effectors which support the $\mathrm{CO}_{2}$ activation of the enzyme and stimulate $\mathrm{CO}_{2}$ fixation. Our results are consistent with this model on the mode of action of these agents. The main objection to such a mechanism that remains to be clarified is, how an enzyme can be catalytically competent under such conditions. The subject of this publication is to contribute to solution of this central question and to investigate characteristic features of the effector binding sites.

The specificity of these sites has been investigated performing structure-activity-studies with a collection of more than 20 of such effectors. The activation constant $K_{\text {act }}\left(\mathrm{CO}_{2}\right)$ and the maximal effector activity, as determined by the dilution method, were taken as indicators for the effectiveness of these compounds. These data correlate fairly well. The essential functional elements of such compounds are two negatively charged groups, as, for example, carboxyl or phosphate residues which may be linked by maximally $6-7 \mathrm{C}$-atoms. Such effectors are structural analogues of the substrate $\mathrm{RuP}_{2}$. Our data present further evidence that $\mathrm{RuP}_{2}$ in addition to its role in the catalysis of $\mathrm{CO}_{2}$ fixation may function as an activator of the Rubisco under certain reaction conditions.

The data in Table I reveal a broad specificity of the effector binding sites. The structural elements of $\mathrm{RuP}_{2}$ obviously can be reduced to its negatively charged terminal groups, because phosphate still is a strong stimulator of the carboxylase.

The effector activity of dicarboxylic acids increases starting from oxalate up to glutarate which is composed of $5 \mathrm{C}$-atoms, similar to $\mathrm{RuP}_{2}$. Our studies show that anions of higher dicarboxylic acids, as for example adipic-, pimelic- or suberic acid do not induce a stimulation effect anymore.

Hydroxy- and $\alpha$-ketodicarboxylic acids which are structurally more closely related to $\mathrm{RuP}_{2}$ usually are more potent effectors than the unsubstituted compounds.

Our experiments with group specific reagents demonstrate that essential amino groups are involved in binding and activity of dianionic effectors. In contrast to the catalysis of $\mathrm{CO}_{2}$ fixation and 
$\mathrm{RuP}_{2}$ binding $[20,21,23]$ the participation of cysteines and arginines could not be detected. These features point to the existence of two positively charged countergroups at the effector binding sites which interact with the negatively charged terminal groups of the dianionic effector molecules. It remains to be clarified, whether or not these countergroups are identical with two reactive lysines that are essential for the binding of the substrate $\mathrm{RuP}_{2}$ at the reaction centers of the carboxylase identified by Hartman and his colleagues [21, 22]. $\mathrm{RuP}_{2}$ and structurally similar effectors, as 6-phosphogluconate which are composed of 5-6 C-atoms apparently span the distance between the reactive amino groups. It has to be established by quantitative binding studies, if in the case of smaller effectors, as bivalent inorganic anions or short dicarboxylic acids, two molecules are bound to the effector sites.

Catalysis and regulation of $\mathrm{CO}_{2}$ fixation also differ in their dependence on the polarity of the reaction medium. If this parameter is decreased by the addition of organic solvents, as methanol, ethanol or acetone, in a concentration range between $1-15 \%(\mathrm{v} / \mathrm{v})$ a modification of the regulation centers of the carboxylase occurs which enhances the affinity of the enzyme for the activator- $\mathrm{CO}_{2}$ and stabilizes the reactive carbamate. This is demonstrated in Figs. 3 and $6 \mathrm{a}$. On the other hand the catalytic process is progressively inhibited with increasing solvent content of the reaction medium (see Figs. $6 \mathrm{a}$ and $\mathrm{b}$ ). The inhibition predominates in the presence of solvents with low dielectric constants, as dioxane or tetrahydrofurane.

The effect of such solvents is obviously similar to the action of dianionic effectors. The stimulation of the $\mathrm{CO}_{2}$ fixation by organic solvents is abolished in the presence of such compounds. We therefore infer, that as a consequence of effector binding to the raction centers a decrease in the polarity is induced at the regulatory sites of the enzyme which modifies the properties of the active lysine for the binding of the ${ }^{\mathrm{A}} \mathrm{CO}_{2}$ presumably by a change of the $\mathrm{pK}$ of this group. This modification may be accomplished by conformational changes of the enzyme that occur on effector binding, as demonstrated fluorimetrically in previous publications $[10,19]$. This conclusion is supported by the findings of Hatch and Jensen [11] that anionic effectors, as 6-phosphogluconate, affect the $\mathrm{pH}$ profile of $\mathrm{CO}_{2}$ activation shifting it towards lower $\mathrm{pH}$ values.
Our results suggest that the central problem concerning the catalytical competence of D-ribulose 1,5-biphosphate carboxylases/oxygenases in the presence of active site directed dianionic effectors can be solved kinetically.

The $\mathrm{CO}_{2}$ activation of the carboxylase proceeds slowly over at least $10-15 \mathrm{~min}$ at $25^{\circ} \mathrm{C}$. Also the dissociation of the enzyme $\cdot{ }^{\mathrm{A}} \mathrm{CO}_{2} \cdot \mathrm{Mg}^{2+}$ complex with a half life time of $20-50 \mathrm{~s}$ is a rather slow process compared to the rapid equilibration of the enzyme with the dianionic effectors listed in Table I.

If one assumes that the rate constants for the dissociation of the carboxylase-effector-complexes are essentially higher than those for the formation of these intermediates the residence time of an effector at the reaction center would be short compared to the lifetime of the activated state of the carboxylase. Under such conditions a relatively low effector concentration is sufficient to interact rapidly with a considerable quantity of enzyme molecules inducing the active conformation. In this way most of the reaction centers remain catalytically competent and the enzyme activity is stimulated. At higher effector concentrations increasing occupation of the reaction centers by effector molecules leads to inhibition even with the enzyme being in a state of higher activation.

This kinetic interpretation of the catalytical competence of the Rubisco under such conditions is supported by the results of our binding studies and activity measurements with effectors. The experiments in Figs. 3-5 demonstrate that low, nonsaturating effector-concentrations induce high activation levels of the carboxylase.

The experimental material so far available points to an unusual mechanism of the complex regulatory processes involved in photosynthetic $\mathrm{CO}_{2}$ fixation which are effective essentially at limiting substrate and effector concentrations. Obviously the homotropic stimulation effect which is induced by the activator $\mathrm{CO}_{2}$ can be regulated heterotropically by active site directed chloroplast metabolites. The physiological relevance of these phenomena needs, however, clarification in more detail.

\section{Acknowledgements}

This work is supported by grant Sa $267(3-4)$ from the Deutsche Forschungsgemeinschaft.

The authors thank Mrs. B. Kablitz and Mrs. L. Pirling for their excellent technical assistance. 
[1] N. G. Pon, B. R. Rabin, and M. Calvin, Biochem. Z. 338, 7-19 (1963).

[2] G. H. Lorimer, M. R. Badger, and T. J. Andrews, Biochemistry 15, 529-536 (1976).

[3] W. A. Laing and J. T. Christeller, Biochem. J. 159, $563-570$ (1976).

[4] G. H. Lorimer, M. R. Badger, and H. W. Heldt in Photosynthetic Carbon Assimilation (H. W. Siegelman and G. Hind, eds.), 283-306, Plenum Press, New York 1978.

[5] B. B. Buchanan and P. Schuermann, J. Biol. Chem. 248, 4956-4964 (1973).

[6] D. K. Chu and J. A. Bassham, Plant Physiol. 54, 556-559 (1974).

[7] D. K. Chu and J. A. Bassham, Plant Physiol. 55, $720-726$ (1975).

[8] F. J. Ryan and N. G. Tolbert, J. Biol. Chem. 250, $4234-4238$ (1975)

[9] R. Chollet and L. L. Anderson, Arch. Biochem. Biophys. 176, 344-351 (1976).

[10] J. Vater and J. Salnikow, Arch. Biochem. Biophys. 194, 190-197 (1979).

[11] A. L. Hatch and R. G. Jensen, Arch. Biochem. Biophys. 205, $587-594$ (1980).

[12] M. R. Badger and G. H. Lorimer, Biochemistry 20, $2219-2225$ (1981).
[13] G. H. Lorimer, Ann. Rev. Plant Physiol. 32, 349-383 (1981).

[14] S. D. McCurry, J. Pierce, N. E. Tolbert, and W. H. Orme-Johnson, J. Biol. Chem. 256, 6623-6628 (1981).

[15] G. H. Lorimer, J. Biol. Chem. 254, 5599-5601 (1979).

[16] H. M. Miziorko, J. Biol. Chem. 254, 270-272 (1979).

[17] G. H. Lorimer and H. M. Miziorko, Biochemistry 19, $5321-5328$ (1980).

[18] G. H. Lorimer, Biochemistry 20, 1236-1240 (1981).

[19] J. Vater, J. Salnikow, and H. Kleinkauf, Biochem. Biophys. Res. Commun. 74, 1618-1625 (1977).

[20] T. Sugiyama, T. Akazawa, N. Nakayama, and Y. Tanaka, Arch. Biochem. Biophys. 125, 107-113 (1968).

[21] J. V. Schloss, C. D. Stringer, and F. C. Hartman, J. Biol. Chem. 253, 5707-5711 (1978).

[22] C. D. Stringer and F. C. Hartman, Biochem. Biophys. Res. Commun. 80, 1043-1048 (1978).

[23] J. V. Schloss, I. L. Norton, C. D. Stringer, and F. C. Hartman, Biochemistry 17, 5626-5631 (1978).

[24] A. K. Saluja and B. A. McFadden, Biochemistry 21, $89-95$ (1982). 